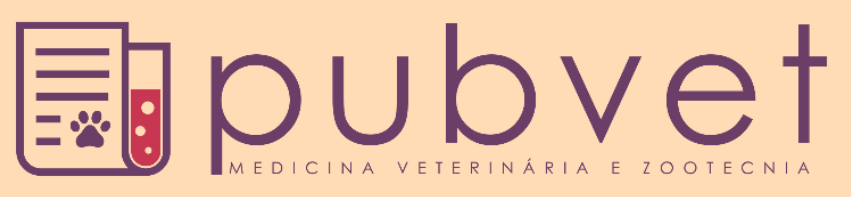

https://doi.org/10.31533/pubvet.v13n09a414.1-10

\title{
Transporte de organismos aquáticos: Procedimento fundamental para desenvolvimento da aquicultura
}

\author{
Marcos Vinícius de Castro Freire ${ }^{*^{*}} \bullet$, Roosevelt de Araújo Sales Júnior ${ }^{1} \bullet$, Maria \\ Gabriela Alves $\operatorname{Costa}^{2}{ }^{\circ}$, Rosane Lopes Ferreira ${ }^{30}$ \\ IDiscente do programa de Pós-Graduação em Ciência Animal - Nível mestrado - Universidade Federal Rural do Semiárido - UFERSA, \\ Centro de Ciências Agrárias. Mossoró - RN, Brasil. \\ ${ }^{2}$ Discente do programa de Pós-Graduação em Produção Animal - Nível mestrado - UFERSA, Centro de Ciências Agrárias. Mossoró - RN, Brasil. \\ ${ }^{3}$ Mestre em Aquicultura e Desenvolvimento Sustentável-Universidade Federal do Paraná-UFPR, Departamento de Zootecnia. Palotina-PR, Brasil. \\ *Autor para correspondência, E-mail: $\underline{\operatorname{marcos} 7 \text { phn@ hotmail.com }}$
}

\begin{abstract}
Resumo. Com os avanços da aquicultura, se capacitar e aprender fazem parte dos critérios para tentar garantir o sucesso do negócio. Se faz necessário implementar práticas de manejo e transporte de organismos aquáticos, ideais ao bem-estar dos animais. Ter conhecimento sobre fisiologia da espécie, parâmetros de qualidade de água e logística operacional, pode diminuir perdas de recursos, insumos e evitar o desgaste na relação com o cliente. Diante disto, este trabalho tem como objetivos (1) Descrever o atual cenário de produção de organismos aquáticos no Brasil, determinando o estado de conhecimento acerca da importância do transporte adequado. (2) Levantar informações preponderantes e determinantes do processo de transporte de organismos aquáticos. (3) Descrever o que a legislação permite. Com intuito de ter informações que sirvam de respaldo para o produtor, ou comunidade cientifica, podendo minimizar perdas no transporte dos organismos, e garantir sucesso na atividade. O estudo se deu através de um levantamento bibliográfico sobre artigos publicados, utilizando as ferramentas de busca na base de dados do Portal de Periódicos da CAPES/MEC, Scielo e Google Acadêmico, além de pesquisas em livros e na legislação. No período temporal de 1984 a 2018. Essas publicações contemplam a realidade do transporte de organismos aquáticos, considerada um item de extrema importância para a atividade produtiva, principalmente para tentar garantir o sucesso do empreendimento.
\end{abstract}

Palavras chave: Bem-estar animal, logística operacional, organismos aquáticos

\section{Transport of aquatic organisms: Fundamental procedure for aquaculture development}

Abstract. With advances in aquaculture, training and learning are part of the criteria to try to ensure business success. It is necessary to implement practices of handling and transport of aquatic organisms, ideal for animal welfare. Having knowledge of species physiology, water quality parameters and operational logistics can reduce resource losses, inputs and avoid wear and tear on customer relationships. Given this, this paper aims to (1) describe the current scenario of production of aquatic organisms in Brazil, determining the state of knowledge about the importance of adequate transportation. (2) To gather preponderant and determinant information on the transport process of aquatic organisms. (3) Describe what the legislation allows. In order to have information that will support the producer, or scientific community, can minimize losses in the transport of organisms, and ensure success in the activity. The study was conducted through a bibliographic survey of published articles, using the search tools in the CAPES/MEC Journal Portal database, 
Scielo and Google Scholar, as well as book searches and legislation from 1984 to 2018. These publications contemplate the reality of the transport of aquatic organisms, considered an extremely important item for the productive activity, mainly to try to guarantee the success of the enterprise.

Keywords: Animal welfare, operational logistics, aquatic organisms

\section{Transporte de organismos acuáticos: Procedimiento fundamental para el desarrollo de la acuicultura}

Resumen. Con los avances en la acuicultura, la capacitación y el aprendizaje son parte de los criterios para tratar de garantizar el éxito empresarial. Es necesario implementar prácticas de manejo y transporte de organismos acuáticos, ideales para el bienestar animal. Tener conocimiento de la fisiología de las especies, los parámetros de calidad del agua y la logística operativa pueden reducir las pérdidas de recursos, los insumos y evitar el desgaste de las relaciones con los clientes. Dado esto, este documento tiene como objetivo (1) Describir el escenario actual de producción de organismos acuáticos en Brasil, determinando el estado del conocimiento sobre la importancia de un transporte adecuado. (2) Recopilar información preponderante y determinante sobre el proceso de transporte de organismos acuáticos. (3) Describa lo que permite la legislación. Para tener información que respalde al productor, o comunidad científica, puede minimizar las pérdidas en el transporte de organismos y asegurar el éxito en la actividad. El estudio se realizó a través de una encuesta bibliográfica de artículos publicados, utilizando las herramientas de búsqueda en la base de datos del portal de revistas CAPES / MEC, Scielo y Google Scholar, así como búsquedas de libros y legislación. En el período comprendido entre 1984 y 2018. Estas publicaciones contemplan la realidad del transporte de organismos acuáticos, considerado un elemento extremadamente importante para la actividad productiva, principalmente para tratar de garantizar el éxito de la empresa.

Palabras clave: Bienestar animal, logística operativa, organismos acuáticos

\section{Introdução}

O desenvolvimento de uma atividade sustentável, além de atender as demandas sociais e ambientais, requer a minimização de custos e o aumento financeiro. Para isso, é imprescindível que os esforços sejam otimizados, sendo importante o investimento no transporte dos organismos. O sistema produtivo aquícola, possui distintas etapas que merecem atenção para se tentar ter a garantia de sucesso na atividade, sendo necessário a implementação de boas práticas de manejo e transporte, que se constitui um dos fatores primordiais para o sucesso dessa importante atividade agropecuária (Baldisserotto, 2013; Tavares-Dias \& Montagner, 2015).

O transporte dos organismos vivos na aquisição inicial para povoamento requer alguns cuidados, pois sem eles o risco de se obter perdas durante o processo ou após o transporte, gerando desperdício de tempo, recursos e equipamentos, é inevitável. Sem falar no desgaste no relacionamento com o cliente. O transporte de animais aquáticos é uma das atividades rotineiras em aquicultura (Baldisserotto, 2013) e merece um olhar especial. A aquicultura deve ser entendida como atividade estratégica por ser uma operação delicada e de alto risco, que envolve cargas vivas de alto valor, demandando equipamentos eficientes, capacitação técnica da mão-de-obra (Goes et al., 2017).

Diante da necessidade de se conhecer aspectos básicos de boas práticas de transporte, de qualidade de água e de logística operacional, este trabalho tem como objetivos (1) Descrever o atual cenário de produção de organismos aquáticos no Brasil, determinando o estado de conhecimento acerca da importância do transporte adequado. (2) Levantar informações preponderantes e determinantes do processo de transporte de organismos aquáticos. (3) Descrever o que a legislação permite. Com intuito de ter informações que sirvam de respaldo para o produtor, ou comunidade cientifica, podendo minimizar perdas e garantir sucesso na atividade. 


\section{Material e métodos}

O estudo se deu por levantamento bibliográfico de artigos publicados, utilizando ferramentas de busca na base de dados do Portal de Periódicos da Coordenação de Aperfeiçoamento de Pessoal de Nível Superior - CAPES (http://www.periodicos.capes.gov.br/), "Scientific Electronic Library Online" Scielo (http://www.scielo.org/php/index.php) e Google Acadêmico (http://scholar.google.com.br/), usando-se a combinação das palavras-chave por pares, em ambos os idiomas, português e inglês, "transport in aquaculture", transporte na aquicultura, "fish transport", transporte de peixes, "shrimp transport", transporte de camarões, "transport of molluscs", transporte de moluscos, "oyster transport", transporte de ostras, "transport of aquatic organisms", transporte de organismos aquáticos, "transport in shrimp farming", transporte na carcinicultura, "transport in fish farming", transporte na piscicultura," transport in oyster farming", transporte na ostreicultura, "transportation in the milleiculture", transporte na mitilicultura. Além disso, foram realizadas pesquisas em livros, na internet e na legislação, filtrando o período temporal de 1984 a 2018, buscando uma maior abrangência de literatura, de trabalhos realizados até 2018, para os principais tipos de organismos aquáticos cultivados.

\section{Panorama da produção aquícola do Brasil}

Segundo dados do IBGE (2017), a produção de pescado no Brasil proveniente da aquicultura, Tabela 1, nos últimos anos foi de: 577.703,973 toneladas em 2014, 595341,598 toneladas em 2015, com queda em 2016 em torno de 584.971,104 toneladas e 559.320,164 toneladas em 2017 (Tabela 1). Essa queda no crescimento é proveniente da estiagem nos principais reservatórios do país.

Tabela 1. Pescado proveniente da aquicultura no Brasil $2014-2017$.

\begin{tabular}{lcccc}
\hline Ano & 2014 & 2015 & 2016 & 2017 \\
\hline Valor, toneladas & 577.703 .973 & 595.341 .598 & 584.971 .104 & 559.320 .164 \\
\hline
\end{tabular}

Fonte: Pesquisa Pecuária Municipal - 2017

Dentro desses valores de 2017, a produção total da piscicultura brasileira foi de 485,2 mil toneladas em 2017, com a tilápia entre as principais espécies produzidas (Figura 1).

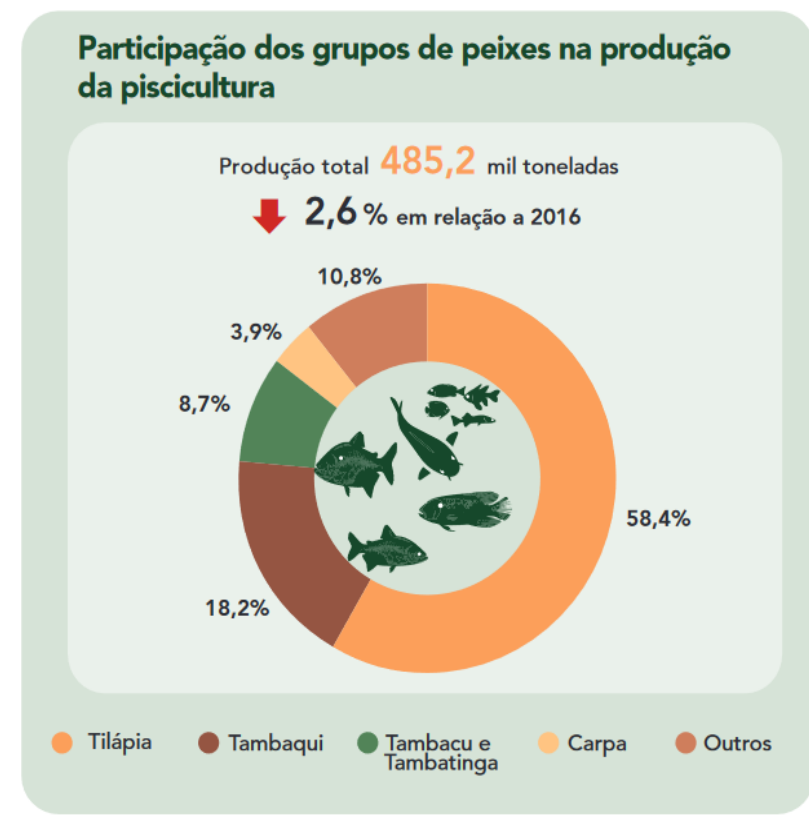

Fonte: IBGE, Diretoria de Pesquisas, Coordenação de Agropecuária, Pesquisa da Pecuária Municipal 2017.

Figura 1. Participação dos grupos de peixes na produção da piscicultura em 2017.

Dentre a produção de crustáceos, o total de camarão produzido pela aquicultura em 2017 foi de: 41,0 mil toneladas, sendo a região Nordeste, Figura 02, a responsável por quase toda a produção do País, com $98,8 \%$ do total nacional (IBGE, 2017). 


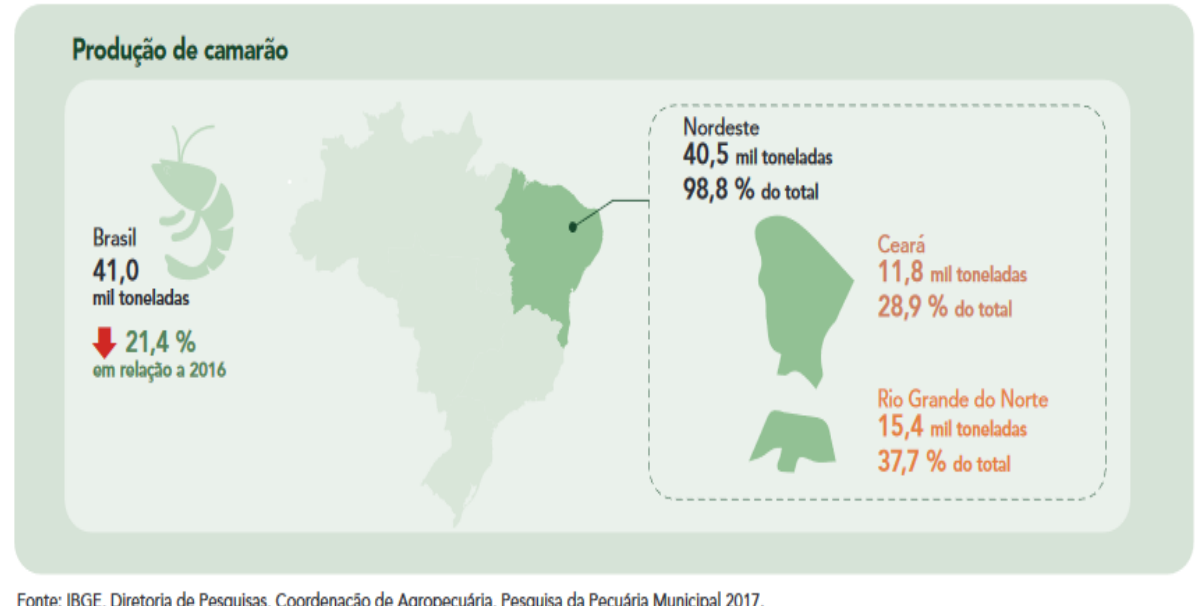

Figura 2. Participação dos grupos de peixes na produção da piscicultura em 2017.

A produção de ostras, vieiras e mexilhões provenientes da aquicultura, segundo IBGE (2017) foi de 20,9 mil toneladas em 2017, com variação positiva de $0,5 \%$ em relação ao ano anterior, tendo Santa Catarina como o principal estado produtor, responsável por $98,1 \%$ da produção brasileira (Figura 3).

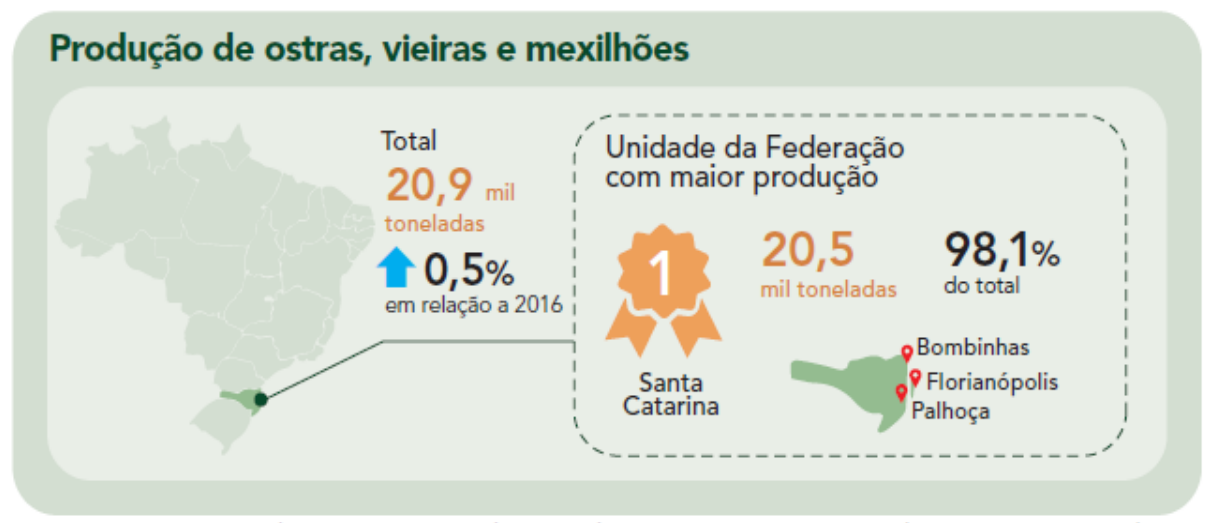

Fonte: IBGE, Diretoria de Pesquisas, Coordenação de Agropecuária, Pesquisa da Pecuária Municipal 2017.

Figura 3: Participação dos grupos de moluscos na produção da piscicultura em 2017.

\section{Legislação para transporte de organismos aquáticos}

Seguir algumas normas de trânsito de animais aquáticos, além de verificar a documentação obrigatória que acompanha o lote dos animais, é imprescindível. Dentro do território nacional, a documentação obrigatória consta no guia de transito animal, atestado sanitário e liberação do IBAMA, dependendo da espécie transportada (Iwashita \& Maciel, 2013).

A Instrução Normativa No 53 do Ministério da Pesca e Aquicultura de 11 de setembro de 2014, determina a obrigatoriedade da Guia de Trânsito Animal (GTA) para animais aquáticos vivos, contém as informações sobre o destino e condições sanitárias, bem como a finalidade do transporte animal. Define como animais aquáticos os peixes, crustáceos, moluscos e outros animais aquáticos destinados à aquicultura, em qualquer fase de seu desenvolvimento na água. Segundo o Art. $2^{\circ}$ A GTA deverá estar acompanhada de Boletim de Produção que conste dados mínimos como: nome e registro profissional do responsável técnico da exploração pecuária, se houver, número total dos animais alojados no sistema de produção de origem do lote. Sendo necessária também, o cadastro dos estabelecimentos, realizadas pelas Secretarias estaduais de Agricultura ou seus órgãos de defesa sanitária animal (Art. 7).

\section{Fisiologia dos organismos e suas respostas}

Os organismos aquáticos, apresentam complexo sistema de defesa, com função de proteger os animais, de infecções e permitir que processos patológicos, infecciosos ou parasitários tenham duração limitada. Reconhecendo corpos estranhos no organismo, metabolizando, neutralizando e as eliminando 
do organismo. Possuem imunidade inata por meio da pele ou muco, e imunidade adquirida através de anticorpos e células de defesa (Forlenza et al., 2011; Iwashita \& Maciel, 2013; Sitjà-Bobadilla, 2008). O estresse promove alterações bioquímicas e fisiológicas, Tabela 2, para adaptação do peixe a novo patamar de equilíbrio para suportar a nova condição introduzida. Essas respostas são separadas em primárias, secundárias e terciárias (Gonçalves et al., 2010).

Tabela 2. Alteração e efeito ocasionados pelo estresse em peixes

\begin{tabular}{lc}
\hline Tipo de alteração & Efeito \\
\hline Primárias & $\begin{array}{c}\text { Liberação de catecolaminas para a circulação } \\
\text { Liberação de cortisol para a circulação }\end{array}$ \\
\hline Secundárias & $\begin{array}{c}\text { Alterações na glicemia } \\
\text { Terciárias }\end{array}$ \\
\hline & $\begin{array}{c}\text { Alterações concentração plasmática de íons } \\
\text { Alterações nos parâmetros hematológicos }\end{array}$ \\
\hline
\end{tabular}

Fonte: Wendelaar Bonga (1997).

O estresse pode ser entendido como a reação biológica do peixe a estímulos ameaçadores, a qual pode variar de acordo com a severidade e duração do estímulo, bem como com a genética e a domesticação dos animais (Takahashi et al., 2006).

\section{Jejum e eliminação de parasitos}

Buscando reduzir perdas de organismos, segundo (Silva et al., 2015) o transporte deve ser realizado o mais rápido possível levando em consideração aspectos como trânsito, horário do dia que vai chegar lá, as condições das estradas, o treinamento do colaborador, aspectos de manejo dos caminhões, tais como: limpeza, desinfecção, climatização. A mortalidade de peixes durante o transporte aumenta os custos de criação (Gomes et al., 2006). Todavia, alguns procedimentos são necessários previamente e se ausentes pode prejudicar todo o sistema. A preparação dos peixes para o transporte muitas vezes é negligenciada, o sucesso da atividade vai depender se os animais foram preparados adequadamente para melhor suportarem o transporte. Segundo Kubitza (2018), dois pontos são de extrema importância a se levar em consideração na preparação prévia ao transporte, são eles o jejum e a eliminação de parasitos. Se tratando de peixes, no período previamente ao transporte, a alimentação dos animais deve deixar de ser fornecida, tendo em vista a diminuição de excretas ricas em amônia e gás carbônico, que podem prejudicar a qualidade da água. Peixes em jejum consomem menos oxigênio que os peixes alimentados. O tempo de jejum depende da temperatura e dos hábitos alimentares (BRASIL, 2005). Em peixes, o jejum prévio, Tabela 3, também se dá em função de que, seu trato digestivo vazio consome praticamente metade do oxigênio comparado aos que foram alimentados (Kubitza, 2018). Além disso, ainda há a vantagem de menos bactérias, provenientes dos restos fecais, serem liberadas na água podendo ocasionar enfermidades futuras.

Tabela 3. Tempo de jejum (em horas) sob diferentes temperaturas

\begin{tabular}{lcccc}
\hline Peso dos peixes & \multicolumn{2}{c}{ Onívoros } & \multicolumn{2}{c}{ Carnívoros } \\
\hline $0,5 \mathrm{~A} 5 \mathrm{~g}$ & $19 \mathrm{a} 23^{\circ} \mathrm{C}$ & $26 \mathrm{~A} 30^{\circ} \mathrm{C}$ & $19 \mathrm{~A} 23^{\circ} \mathrm{C}$ & $26 \mathrm{~A} 30^{\circ} \mathrm{C}$ \\
$10 \mathrm{~A} 100 \mathrm{~g}$ & $24 \mathrm{a} \mathrm{36} \mathrm{h}$ & $16 \mathrm{a} 24 \mathrm{~h}$ & $36 \mathrm{~A} 48 \mathrm{~h}$ & $24 \mathrm{a} 36 \mathrm{~h}$ \\
$200 \mathrm{a} 2000 \mathrm{~g}$ & $36 \mathrm{~A} 48 \mathrm{~h}$ & $24 \mathrm{a} \mathrm{36h}$ & $48 \mathrm{a} 60 \mathrm{~h}$ & $36 \mathrm{~A} 48 \mathrm{~h}$ \\
\hline
\end{tabular}

Fonte: Kubitza (2018).

Para camarões, as larvas devem ser alimentadas com náuplios de artêmia, sendo que o jejum completo pode provocar o canibalismo (Barbieri Júnior \& Ostrensky Neto, 2002) Para os moluscos filtradores, como as ostras, que se alimentam filtrando a água e capturando organismos microscópicos: fitoplâncton, que são microalgas, zooplâncton, que são os protozoários e ainda partículas orgânicas 
(Lachi \& Sipaúba-Tavares, 2008; Santeiro, 2005), as larvas são alimentadas com microalgas, geralmente produzidas em sepário, que nutrem as larvas em cada fase. Se forem coletadas em ambiente natural, e a distância for curta, o recomendado é que sejam transportadas sem alimento, apenas envolvidas por esponjas umedecidas com o propósito de evitar o ressecamento (Cardoso Júnior et al., 2012).

Para a eliminação de parasitos, uma das técnicas recomendadas é a depuração da água dos tanques com água salinizada, em quantidade de 6 e $8 \mathrm{~g}$ de sal $/ 1$ ou 6 a $8 \mathrm{~kg} \mathrm{de} \mathrm{sal} / \mathrm{m}^{3}$, reduz a ocorrência de infecções por bactérias e fungos. Outra forma de eliminação de parasitas, é a utilização do sal que tem efeito profilático sendo indicado para o tratamento de fungos, infestação de parasitas monogenéticos, lernea, infecção branquial bacteriana, entre outras, ajudando também a reduzir o estresse. Outra possibilidade de eliminação de parasitos, como tricodinas e monogenoides, é através de banho de 30 minutos em água contendo permanganato de potássio, na concentração de 3 a $4 \mathrm{~g} / \mathrm{m}^{3}$ ou 3 a $4 \mathrm{mg} / \mathrm{l}$ (Gomes et al., 2002; Kubitza, 2018; Salbego et al., 2014; Tavares-Dias \& Montagner, 2015). Além disso, existem inúmeros benefícios do uso de cloreto de sódio na água como vistos por Barton \& Zitzow (1995) e Carneiro \& Urbinati (2001).

\section{Transporte}

Os peixes, com densidade variando em função da espécie e do tamanho, são acondicionados em embalagens plásticas, contendo $1 / 4$ de água e $3 / 4$ de oxigênio com peso, devendo ser de tubo pressurizado, mas sem manter o saco plástico com muita pressão interna, protegidos em caixas e transportados, por carros, ônibus, caminhões ou avião (BRASIL, 2005). A saída das pós-larvas do ambiente do laboratório para o ambiente das fazendas é importante tanto sob o aspecto de biossegurança quanto de boas práticas de manejo. O processo de expedição de pós-larvas de camarão se inicia um ou dois dias antes do envio propriamente dito, pela aclimatação prévia das larvas, as quais devem, preferencialmente, ser embaladas em condições de salinidade e $\mathrm{pH}$ próximas às da fazenda que irá recebê-las. Para camarões marinhos, a exigência do produtor ao laboratório de informações dos principais parâmetros de transporte, tais como densidade dos animais nos sacos de transporte, qualidade da larva, estágio e quantidade de alimento adicionado em cada saco (Barbieri Júnior \& Ostrensky Neto, 2002) são primordiais. Os sacos de 30 litros devem ser transportados em caixas térmicas com 12 litros de água e o resto de oxigênio puro, com náuplios de artêmia e temperatura de 20 a $24^{\circ} \mathrm{C}$, e carvão ativado (Olin \& Fast, 1992; Robertson et al., 1987; Smith \& Ribelin, 1984) para o transporte de pós-larvas, as empresas utilizam caixas transportadoras e realizam processos de sanitização nos apetrechos, água e veículos envolvidos no transporte (ABCC, 2017). Para ostras o transporte o acondicionamento para o transporte deve ser feito em caixas refrigeradas, evitando a exposição direta ao sol (Kubitza, 2018).

\section{Aspectos de qualidade de água}

Apesar de o cultivo adequado ser essencial para a sobrevivência dos animais, é importante que se pense também no bem-estar durante o transporte, tendo-se um controle na qualidade da água (Bittencourt et al., 2018), visando gerar o mínimo de estresse aos organismos, para que não haja perdas, levando-se em consideração que qualquer alteração em algum parâmetro nas unidades de transporte, pode agravar a situação de bem-estar dos animais, tão como a densidade excessiva que deve ser calculada em função do volume de água levando em consideração as respostas fisiológicas geradas pelo estresse do transporte (Carneiro \& Urbinati, 2001; Patterson et al., 2003), sendo preciso que conheça os aspectos fisiológicos da espécie.

O ideal é que as Pls possuam salinidade e $\mathrm{pH}$ da água próximos aos da água do cultivo da fazenda que serão transferidas. É necessária também a utilização de carvão natural, que ajuda a reduzir o impacto na qualidade de água e de náuplios de artêmia. O Tris (Hydroximetil Amino-Metano), pode ser utilizado para evitar a variação de $\mathrm{pH}$. Para camarões marinhos a temperatura da água deve ser de $24^{\circ} \mathrm{C}$ para transporte curto de até 4 horas, $22^{\circ} \mathrm{C}$ para transportes com duração de 12 horas, ou $20^{\circ} \mathrm{C}$ para transportes superiores a 20 horas. $\mathrm{O}$ uso de gelo pode ser utilizado para controlar a temperatura (Barbieri Júnior \& Ostrensky Neto, 2002). A variação da temperatura é um dos desafios que influencia bastante no transporte dos peixes, assim como a acidificação da água, o aumento da amônia e a baixa quantidade de oxigênio. A parte da amônia que oferece maior risco aos organismos, por ser mais tóxica, é a forma não ionizada NH3 (Araújo et al., 2017). Ambos devem se manter no padrão de cada espécie, para que ocorra 
a transferência sem perturbações que possam causar a morte dos animais. A maioria dos peixes tropicais apresentam bom desenvolvimento em águas com valores de concentração de oxigênio dissolvido na água variando entre 3,7 a 5,1 mg/L (Almeida et al., 2016).

\section{Aditivos}

Os anestésicos reduzem a atividade e o metabolismo dos peixes durante as operações relacionadas ao transporte, reduzindo as injúrias físicas, o consumo de oxigênio e a excreção de metabólitos tóxicos. A adição de anestésicos na água utilizada para o transporte de peixes pode prevenir ou mitigar os efeitos nocivos do estresse de transporte (Kubitza, 1999; Salbego et al., 2017), prática cada vez mais utilizada na aquicultura, em função desses aditivos promoverem uma maior sobrevivência, integridade física e bem-estar dos animais.

Os sais, cloreto de magnésio e o sulfato de magnésio, em concentrações adequadas melhoram a condição e a sobrevivência, diminuindo o consumo de oxigênio e excreta de nitrogênio reduzindo a mortalidade, servindo como relaxante acessível e de fácil manipulação (Arafa et al., 2010; Gleadall, 2013). Também são utilizados alguns extratos vegetais vendidos comercialmente para camarões, como o Eugenol, óleo de cravo, óleos essenciais de Aloysia triphylla e Lippia alba. Tabela 4.

Tabela 4. Tempo de jejum (em horas) sob diferentes temperaturas

\begin{tabular}{llcll}
\hline Tipo & Nome & Concentração Animal & Autores \\
\hline Anestésico & Aloysia triphylla & $20-30 \mu / \mathrm{L}$ & Camarão (Litopenaeus vannamei) & Parodi et al. (2014) \\
Anestésico & Benzocaína & $50-80 \mathrm{mg} / \mathrm{L}$ & Ostras (Pinctadamargaritifera e Pinctadafucata) & Acosta-Salmón et al. (2005) \\
Anestésico & Eugenol & $1,3 \mathrm{mg} / \mathrm{L}$ & Camarão (Fenneropenaeus sindicus) & Akbari et al. (2010) \\
Anestésico & Óleo de cravo & $125-250 \mathrm{mg} / \mathrm{L}$ & Camarão (Macrobrachium rosembergii) & Vartak \& Singh (2006) \\
Anestésico & Lippia alba & $<100 \mu / \mathrm{L}$ & Camarão (Litopenaeus vannamei) & Parodi et al. (2014) \\
Anestésico & Cloreto de sódio, $\mathrm{NaCl}$ & $8000 \mathrm{mg} / \mathrm{L}$ & Colossoma macropomum) & Gomes et al. (2003) \\
Vitamina & Vitamina C & $1000 \mathrm{mg} / \mathrm{kg}$ & Tilápia do Nilo (Oreochromis niloticus) & Okamura et al. (2007) \\
\hline
\end{tabular}

${ }^{\mathrm{I} A d i c i o n a d a ~ n a ~ r a c ̧ a ̃ o ~} 14$ dias antes do transporte. Fonte: Elaborada pelos autores.

\section{Logística operacional}

A logística organizacional e operacional do processo é um fator determinante para se atingir uma qualidade nos serviços de distribuição aos clientes, através das atividades de planejamento, organização e controle na movimentação do produto (Carlini Júnior et al., 2003). O transporte, está relacionado com a movimentação dos organismos vivos, dentro da cadeia logística entre diferentes pontos (Goes et al., 2015), devendo ser realizado em recipientes distintos em função do percurso e da quantidade de animais, utilizando boas práticas de manejo do transporte dos organismos, calculando o tempo de viagem tal como utilização de equipamentos adequados e confiáveis, e pensando nos imprevistos que possam vir a acontecer. É responsável pelo sucesso ou fracasso desta cadeia, devido ao seu alto custo, o transporte que, se bem executado, é um dos fatores-chave para a rentabilidade da cadeia produtiva (Goes et al., 2015).

O ideal é fazer o planejamento em alinhamento, junto ao laboratório, pleno com a estratégia coorporativa e filosófica da empresa, visando receber os animais em horários mais frescos do dia, para realizar as práticas de manejo, priorizando alternativas de níveis de serviços mais adequadas, tais como: frequência e horários de entrega, formas de consolidação de cargas e o tipo de frota, destacando se o serviço é próprio ou terceirizado (Iwashita \& Maciel, 2013; Martins \& Xavier, 2011), sendo o transporte deve ser realizado o mais rápido possível, a fim de reduzir as perdas de qualidade. Além disso, na realização desta etapa, devem-se considerar as condições das estradas, o treinamento do colaborador e os aspectos da manutenção e sanitários dos caminhões, tais como: limpeza, desinfecção, climatização (Silva et al., 2015).

\section{Considerações finais}

Com a expansão da aquicultura no Brasil nas últimas duas décadas, se fez cogente o aprofundamento nos conhecimentos e tecnologias, que pudessem melhorar o setor e fazê-lo crescer. Vários aspectos relevantes melhoram o transporte dos organismos aquáticos, seus efeitos podem variar conforme a 
espécie, mas por mais simples que sejam não devem ser ignorados, buscando acondicionamento dos animais, visando o bem-estar animal e tendo em vista a qualidade e sucesso da produção.

\section{Referências bibliográficas}

ABCC. 2012. - Associação Brasileira de Criadores de Camarão. 2012. Curso de Boas práticas de Manejo e Biossegurança: Laboratórios de maturação, Reprodução e Larvicultura de camarão. ABCC. Ministério da Pesca e Aquicultura. Natal - RN.

ABCC. 2017. - Associação Brasileira de Criadores de Camarão. 2017. Censo da carcinicultura do litoral norte do estado do Ceará e zonas interioranas adjacentes 2015/2016. Natal - RN.

Acosta-Salmón, H., Martínez-Fernández, E. \& Southgate, P. C. (2005). Use of relaxants to obtain saibo tissue from the blacklip pearl oyster (Pinctada margaritifera) and the Akoya pearl oyster (Pinctada fucata). Aquaculture, 246(1-4):167-172.

Akbari, S., Khoshnod, M. J., Rajaian, H. \& Afsharnasab, M. (2010). The use of eugenol as an anesthetic in transportation of with Indian shrimp (Fenneropenaeus indicus) post larvae. Turkish Journal of Fisheries and Aquatic Sciences, 10(3):423-429.

Almeida, E. M., Machado, A. S. \& Rios, A. D. F. (2016). Efeito do transporte em peixes. Nutritime Revista Eletrônica, 134764-4772.

Arafa, S., Limam, Z., Selmi, S., Sadok, S. \& El Abed, A. (2010). Metabolic activity variations in the sea urchins (Paracentrotus lividus) treated with magnesium and subjected to handling stress and aerial exposure. Aquaculture Research, 41(9):1273-1281.

Araújo, J. G., Santos, M. A. S., Rebello, F. K. \& Isaac, V. J. (2017). Cadeia comercial de peixes ornamentais do Rio Xingu, Pará, Brasil. Boletim do Instituto de Pesca, 43(2):297-307.

Baldisserotto, B. (2013). Fisiologia de peixes aplicada à piscicultura (Vol. 1). Santa Maria: Universidade Federal de Santa Maria.

Barbieri Júnior, R. C. \& Ostrensky Neto, A. (2002). Camarões marinhos: engorda (Vol. 1). Viçosa, Minas Gerais, Brasil: Aprenda Fácil.

Barton, B. A. \& Zitzow, R. E. (1995). Physiological responses of juvenile walleyes to handling stress with recovery in saline water. The Progressive Fish-Culturist, 57(4):267-276.

Bittencourt, F., Damasceno, D. Z., Lui, T. A., Signor, A., Sanches, E. A. \& Neu, D. H. (2018). Water quality and survival rate of Rhamdia quelen fry subjected to simulated transportation at different stock densities and temperatures. Acta Scientiarum. Animal Sciences, 401-8.

BRASIL. 2005. - Secretaria Especial de Aquicultura e Pesca. 2005. Boas Práticas de Manejo em Aquicultura. Itaipu Binacional. Paraná, Brasil.

BRASIL. Instrução Normativa No 53 do Ministério da Pesca e Aquicultura de 11 de setembro de 2014. Determinar a obrigatoriedade da Guia de Trânsito Animal (GTA) para amparar o transporte de animais aquáticos vivos e matéria-prima de animais aquáticos provenientes de estabelecimentos de aquicultura e destinados a estabelecimentos registrados em órgão oficial de inspeção e aprova o modelo de Boletim de Produção. Brasília, 11 de setembro de 2014.

Cardoso Júnior, L. O., Lavander, H. D., Silva Neto, S. R., Souza, A. B., Silva, L. O. B. \& Gálvez, A. O. (2012). Crescimento da ostra Crassostrea rhizophorae cultivada em diferentes densidades de estocagem no Litoral Norte de Pernambuco. Pesquisa Agropecuária Pernambucana, 17(1):10-14.

Carlini Júnior, R. J., Costa, M. T., Fávero, L. A., Lisboa Filho, W. \& Lucena, H. A. (2003). Integração logística na cadeia produtiva do camarão: O caso da Netuno no Estado de Pernambuco. SOBER4-17.

Carneiro, P. C. F. \& Urbinati, E. C. (2001). Salt as a stress response mitigator of matrinxã, Brycon cephalus (Günther), during transport. Aquaculture Research, 32(4):297-304.

Forlenza, M., Fink, I. R., Raes, G. \& Wiegertjes, G. F. (2011). Heterogeneity of macrophage activation in fish. Developmental \& Comparative Immunology, 35(12):1246-1255.

Gleadall, I. G. (2013). Low dosage of magnesium sulphate as a long-term sedative during transport of firefly squid, Watasenia scintillans. Journal of Experimental Marine Biology and Ecology, 447138139. 
Goes, E. S. R., Lara, J. A. F., Gasparino, E., Del Vesco, A. P., Goes, M. D., Alexandre Filho, L. \& Ribeiro, R. P. (2015). Pre-slaughter stress affects ryanodine receptor protein gene expression and the water-holding capacity in fillets of the Nile tilapia. PloS one, 10(6):e0129145.

Goes, G. A., Oliva, R. A., Ronqui, R. G., Queiroz, T. R. \& Satolo, E. G. (2017). Descrição do sistema logístico de transporte: Uma análise conceitual envolvendo piscicultura. South American Development Society Journal, 1(2):100-115.

Gomes, L. C., Araujo-Lima, C. A. R. M., Chippari-Gomes, A. R. \& Roubach, R. (2006). Transportation of juvenile tambaqui (Colossoma macropomum) in a closed system. Brazilian Journal of Biology, 66(2A):493-502.

Gomes, L. C., Araujo-Lima, C. A. R. M., Roubach, R. \& Urbinati, E. C. (2003). Avaliação dos efeitos da adição de sal e da densidade no transporte de tambaqui. Pesquisa Agropecuária Brasileira, 38283-290.

Gomes, L. C., Roubach, R. \& Lima, C. A. (2002). O sal de cozinha no transporte de peixes. Revista Panorama da Aquicultura, 1250-51.

Gonçalves, A. F. N., Takahashi, L. S., Urbinati, E. C., Biller, J. D. \& Fernandes, J. B. K. (2010). Transporte de juvenis de curimbatá Prochilodus lineatus em diferentes densidades. Acta Scientiarum. Animal Sciences, 32(2):205-211.

IBGE. 2017. - Instituto Brasileiro de Geografia e Estatística. 2017. PPM - Produção Pecuária municipal. Rio de Janeiro, Brasil.

Iwashita, M. K. P. \& Maciel, P. O. (2013). Princípios básicos de sanidade de peixes. In A. P. O. Rodrigues, A. F. Lima, A. L. Alves, D. K. Rosa, L. S. Torati \& V. R. V. Santos (Eds.), Piscicultura de água doce: multiplicando conhecimento, Brasília, Distrito Federal, Brasil. ed., 7, p. 215-269. Brasília, Brasil: Embrapa.

Kubitza, F. (1999). Nutrição e alimentação dos peixes cultivados (Vol. 1). Campo Grande, Mato Grosso do Sul.

Kubitza, F. (2018). Transporte de peixes vivos: condicionamento da água, preparo dos peixes e cuidados na operação. Revista Panorama da Aquicultura, 2814-21.

Lachi, G. B. \& Sipaúba-Tavares, L. H. (2008). Qualidade da água e composição fitoplanctônica de um viveiro de piscicultura utilizado para fins de pesca esportiva e irrigação. Boletim do Instituto de Pesca, 34(1):29-38.

Martins, R. S. \& Xavier, W. S. (2011). Atributos do serviço de transporte no relacionamento indústriavarejo. Revista Brasileira de Gestão de Negócios, 13(39):193-204.

Okamura, D., Araújo, F. G., Logato, P. V. R., Murgas, L. D. S., Freitas, R. T. F. \& Araújo, R. V. (2007). Efeito da vitamina $\mathrm{C}$ sobre o hematócrito e glicemia de alevinos de tilápia-do-nilo (Oreochromis niloticus) em transporte simulado. Arquivo Brasileiro de Medecina Veterinária e Zootecnia, 59(4):883-888.

Olin, P. G. \& Fast, A. W. (1992). Penaeid PL harvest, transport, acclimation and stocking. In A. W. Fast \& L. J. Lester (Eds.), Marine Shrimp Culture: Principles and Practices (pp. 301-320): Elsevier Science Publishers.

Parodi, T. V., Cunha, M. A., Becker, A. G., Zeppenfeld, C. C., Martins, D. I., Koakoski, G., . . . Baldisserotto, B. (2014). Anesthetic activity of the essential oil of Aloysia triphylla and effectiveness in reducing stress during transport of albino and gray strains of silver catfish, Rhamdia quelen. Fish Physiology and Biochemistry, 40(2):323-334.

Patterson, R. N., Watts, K. C. \& Gill, T. A. (2003). Micro-particles in recirculating aquaculture systems: determination of particle density by density gradient centrifugation. Aquacultural Engineering, 27(2):105-115.

Robertson, L., Bray, W. A. \& Lawrence, A. L. (1987). Shipping of penaeid broodstock: water quality limitations and control during 24 hour shipments. Journal of the World Aquaculture Society, 18(2):45-56.

Salbego, J., Becker, A. G., Gonçalves, J. F., Menezes, C. C., Heldwein, C. G., Spanevello, R. M. \& Heinzmann, B. M. (2014). The essential oil from Lippia alba induces biochemical stress in the silver catfish (Rhamdia quelen) after transportation. Neotropical Ichthyology, 12(4):811-818. 
Salbego, J., Toni, C., Becker, A. G., Zeppenfeld, C. C., Menezes, C. C., Loro, V. L. \& Baldisserotto, B. (2017). Biochemical parameters of silver catfish (Rhamdia quelen) after transport with eugenol or essential oil of Lippia alba added to the water. Brazilian Journal of Biology, 77(4):696-702.

Santeiro, R. M. (2005). Impacto ambiental da piscicultura na qualidade da água e na comunidade planctônica. PhD, Universidade Estadual Paulista "Júlio de Mesquita Filho", Jaboticabal.

Silva, R. C., Nascimento, J. W. B., Oliveira, D. L. \& Furtado, D. A. (2015). Termohygrometry on the transportation and eggs quality for human consumption. Revista Brasileira de Engenharia Agrícola e Ambiental, 19(7):668-673.

Sitjà-Bobadilla, A. (2008). Living off a fish: a trade-off between parasites and the immune system. Fish \& Shellfish Immunology, 25(4):358-372.

Smith, T. I. J. \& Ribelin, B. (1984). Stocking density effects on survival of shipped postlarval shrimp. The Progressive Fish-Culturist, 46(1):47-50.

Takahashi, L. S., Abreu, J. S., Biller, J. D. \& Urbinati, E. C. (2006). Efeito do ambiente pós-transporte na recuperação dos indicadores de estresse de pacus juvenis, Piaractus mesopotamicus. Acta Scientiarum. Animal Sciences, 28(4):469-475.

Tavares-Dias, M. \& Montagner, D. B. (2015). Uso e principais aplicações do sal comum na piscicultura de água doce. Embrapa Amapá-Documentos, 891-38.

Vartak, V. \& Singh, R. K. (2006). Anesthetic effects of clove oil during handling and transportation of the freshwater prawn, Macrobrachium rosenbergii (de man). Israel Journal of Aquaculture, 584654.

Wendelaar Bonga, S. E. (1997). The stress response in fish. Physiological Reviews, 77(3):591-625.

Recebido: 11 de setembro, 2019.

Aprovado: 10 de outubro, 2019.

Publicado: 4 de novembro, 2019.

Licenciamento: Este artigo é publicado na modalidade Acesso Aberto sob a licença Creative Commons Atribuição 4.0 (CC-BY 4.0), a qual permite uso irrestrito, distribuição, reprodução em qualquer meio, desde que o autor e a fonte sejam devidamente creditados. 